\title{
Memorabilia
}

\section{AULA INAUGURAL DO SEGUNDO SEMESTRE LETIVO DE 2011 DO PROGRAMA DE PÓS-GRADUAÇÃO EM DIREITO DA UNIVERSIDADE FEDERAL DE MINAS GERAIS}

\section{Elos de solidariedade}

Elza Maria Miranda Afonso ${ }^{1}$

\section{Agradecimentos}

Agradeço o convite para proferir a Aula Inaugural do Programa de Pós-Graduação.

Ele muito me honra e constitui motivo de grande alegria para mim.

Agradeço aos Coordenadores, aos Professores, estudantes e funcionários da Pós-Graduação e da Faculdade.

Vou falar um pouco de passado e de presente, e um pouco de promessas e esperanças, que nos apontam para o futuro.

Então, ao agradecer aos que aqui estão, agradeço, também, aos que fizeram a história da Pós-Graduação e desta Casa e aos que nos precederam na jornada para a eternidade.

Ao me unir a eles, na lembrança, tomo por empréstimo os versos de Cecília Meireles, no poema $5^{\circ}$ Motivo da Rosa:

[...] vivemos do que perdura, não do que fomos. Desse acaso,

1 Professora aposentada da Faculdade de Direito da Universidade Federal de Minas Gerais. Doutora em Direito pela Universidade Federal de Minas Gerais. Autora de O positivismo na epistemologia jurídica de Hans Kelsen (Belo Horizonte, Faculdade de Direito da Universidade Federal de Minas Gerais, 1984). 
do que foi visto e amado: - o prazo

do Criador na criatura ... ${ }^{2}$

\section{2. "Nenhum homem é uma ilha"}

$\mathrm{Li}$, pela primeira vez, o maravilhoso trecho do escritor inglês nascido no século XVI, John Donne, no pórtico do livro de Ernest Hemingway, Por Quem os Sinos Dobram. Desse trecho, Hemingway tirou o título de seu livro, For Whom the Bell Tolls:

Nenhum homem é uma ilha, completo em si mesmo. Cada homem é uma peça do continente, uma parte do todo. Se um torrão de terra é levado pelo mar, a Europa fica diminuída, como se fosse um promontório, como se fosse o solar de teus amigos, ou o teu próprio solar. A morte de cada homem me diminui, porque sou parte da humanidade. Por isso, não perguntes por quem os sinos dobram. Eles dobram por ti. ${ }^{3}$

Depois de lê-lo, comecei a procurá-lo.

Anos depois o encontrei, no livro Meditações.

Estava na Meditação 17, em meio a evocações e divagações, como um diamante raro, reluzindo no meio de cascalhos.

Ele fora salvo por alguém por meio de um verdadeiro trabalho de garimpo.

Certamente varou as fronteiras do tempo e do espaço porque foi preservado no frontispício do romance de Hemingway, de 1940, que tem como cenário a Guerra Civil Espanhola e, como tema, a própria condição humana.

2 MEIRELES, Cecília. Obra poética. Rio de Janeiro: Nova Aguilar, 1987, p. 278.

3 DONNE, John. Meditações. Trad. Fábio Cyrino. São Paulo: Landmark, 2007, p. 104. No original: "No man is an island, entire of itself; every man is a piece of the continent, a part of the main. If a clod be washed away by the sea, Europe is the less, as well as if promontory were, as well as if a manor of thy friends or of thine own were. Any man's death diminishes me, because I am involved in mankind; and therefore never send to know for whom the bell tolls; it tolls for thee." 
Pensei, então: que extraordinário trabalho, muitas vezes anônimo e silencioso, de recolher e preservar o que a humanidade produz de precioso, que pavimenta as vias de acesso aos bens da cultura, que reparte o pão para alimentar o nosso espírito, transpondo as barreiras do tempo e superando as do espaço.

Companheiros de um mesmo destino, os elos que nos unem e nos fazem um pouco menos fragmentados, um pouco mais inteiros, um pouco mais completos em nossos ideais e em nossos sonhos, se manifestam em muitos planos de nossa vida.

Precisamos do outro, não só em virtude de nossas imperfeições, mas, também, para podermos realizar e vivenciar os nossos projetos, os nossos tesouros espirituais, as nossas esperanças, os nossos sonhos, o nosso amor.

\section{Os vínculos da solidariedade}

No século IV a.C., Aristóteles tentou explicar, na Política, a sociabilidade humana.

Para ele, era evidente que o homem é um animal político porque possui o dom da palavra, que serve para expressar o útil e o prejudicial, o bem e o mal, o justo e o injusto. ${ }^{4}$

No século XX, Jacques Maritais, cujas contribuições nos chegaram por meio do Professor Edgar de Godoi da Mata-Machado, retoma o diálogo com Aristóteles, mas ressalta que, ao contrário das interpretações que partiam de suas assertivas, a inclinação natural do ser humano para viver em sociedade não resulta somente de suas fragilidades e de suas indigências. Resulta, também, da necessidade que ele tem de se abrir nas comunicações do conhecimento e do amor.

4 ARISTÓTELES. Política. In: Obras. Madrid: Aguilar S.A, 1982, I, II, p. 680. 
As pessoas se interrelacionam não somente para suprir as suas carências, mas, também, para compartilhar os seus dons e as suas riquezas. ${ }^{5}$

Descobrimos, a cada passo, que a vida é uma corrente feita de elos de solidariedade. Descobrimos, também, que, em nenhum outro plano a solidariedade se revela de modo tão amplo, tão livre, tão abnegado e, às vezes, tão anônimo, como no mundo da cultura, do saber, da pesquisa, do conhecimento.

A Universidade propicia essa revelação, tanto quando, em seus recintos, buscamos o conhecimento, como quando percebemos que ele não pode ficar preso dentro de seus muros, não nos pertence, não pode ser apropriado por ninguém, porque pertence a todos, pertence à cultura, pertence ao acervo dos bens que se tornam patrimônio da Humanidade.

Os diálogos que se tecem no campo da cultura não têm fronteiras, nem no tempo, nem no espaço, não têm barreiras entre a vida e a morte.

Neles reunimos os antigos e os contemporâneos.

Por eles, vemos o pensamento jurídico caminhando na história, buscand o fundamentos para o Direito, distinguindo natureza e convenção, delineando concepções de Justiça, desenhando os esboços do conceito de pessoa humana, de sua dignidade, de seus direitos.

Nos legados perenes que recebemos, podemos dialogar com os antigos, com os medievais, com os modernos e com os contemporâneos, com várias constelações que lançaram luzes em nossos caminhos e nos ajudaram a formar as nossas convicções e a nossa visão de mundo.

5 MARITAIN, Jacques. La personne et le bien commun. Paris: Desclée de Brouwer, 1947, pp. 42-43. MATA-MACHADO, Edgar de Godoi da. Contribuição ao personalismo jurídico. Belo Horizonte: Del Rey, 1999. 


\section{A preservação e a criação do saber}

A cultura, diz Recaséns Siches, é a "herança social utilizada, revivida e modificada". ${ }^{6}$

Cultura é a realidade que adquiriu valor, transformada pela mão do homem e impregnada de significados. Sobre ela, Bobbio escreve: "A cultura representa tudo aquilo que expressa em seu maior grau as faculdades criadoras do homem". ${ }^{7}$

No mundo da cultura, que é o mundo humano, no recolhimento e na atribuição de significados, na transformação da realidade, na conservação e na inovação, é inevitável que surjam divergências no campo das ideias e que surjam impasses gerados pelo confronto entre o velho e o novo.

Divergências sempre estiveram presentes, desde a Grécia antiga, entre doutrinas, teorias e correntes. E não somente entre conceitos contrários ou contrapostos, como Direito Natural e Direito Positivo, mas com relação ao mesmo conceito, como nos estudos do Direito Natural, as diversas doutrinas sobre os seus diferentes fundamentos, e no estudo do Positivismo Jurídico, os diversos matizes de doutrinas e correntes.

O embate entre o velho e o novo, entre o que ficou sedimentado e o que rompe tradições, encontra momentos fascinantes na história humana, em que o conhecimento foi recolhido e preservado, se desdobrou em novos prismas, cresceu, se renovou e inovou.

A história é um palco fantástico de manifestação da força criadora do espírito humano, mas é, também, um es-

6 RECASÉNS SICHES, Luis. Tratado general de filosofía del derecho. México: Porrua, 1975, p. 106.

7 BOBBIO, Norberto. O tempo da memória: de senectude e outros escritos autobiográficos. Rio de Janeiro: Campus, 1997, p. 114. 
petáculo cruento de guerras sangrentas e de dominação, de destruição e de renascimento.

O século VI, da era cristã, oferece um bom exemplo desses paradoxos.

Em meio às ruínas do Império Romano do Ocidente que, com a invasão dos bárbaros, desabava, surgem os mosteiros que iriam se transformar em centros de preservação do conhecimento e do saber. Ali, a literatura clássica do mundo antigo era recolhida, restaurada, mantida e preservada para as gerações futuras.

Em magníficas páginas de sua História Universal, H. G. Wells - o mesmo escritor criador da moderna ficção científica - relata como, em meio às ruínas que se alastram pelas instituições, ocorre a salvação do saber pelo cristianismo.

O monaquismo ocidental iria popularizar a educação, iria criar escolas e iria substituir o trabalho do escravo culto pelo trabalho abnegado de pessoas livres. Dos mosteiros beneditinos, diz Wells: "Por toda parte os encontramos como centros de luz, restaurando, mantendo e elevando o padrão da cultura $[\ldots]^{\prime \prime} .8$

Por oito séculos, o sistema monástico evitou que o mundo se transformasse em caos e, no raiar do século XIII, as escolas a ele associadas iriam se transformar nas universidades medievais.

Este é um momento admirável da história. A cultura, que nasce, por toda parte, pela violência, quando o Senhor interpõe, entre ele e a natureza, o escravo, em uma dialética de dominação, começa a dar sinais de que dela pode se libertar.

No mesmo século VI, no Império Romano do Oriente, Justiniano fez construir, com a compilação da jurisprudência

8 WELLS, H.G. História universal. Vol. III. Trad. Anísio Teixeira. São Paulo: Nacional, 1972, p. 877. 
romana dos séculos I e II da era cristã, o grande monumento que iria perenizar o Direito Romano, o Corpus Iuris Civilis, com seus quatro livros, o Digesto ou Pandectas, as Institutas, o Codex e as Novelas.

As Institutas são um resumo do Digesto, destinadas aos estudantes. Foram dedicadas pelo Imperador “à Juventude do Império Romano, ávida de leis". ${ }^{9}$

Ali, nas Institutas e no Digesto, estão as fórmulas cunhadas pela jurística romana, que se entranharam na cultura ocidental e que encontramos repetidas até hoje:

Iustitia est constans et perpetua voluntas ius suum cuique tribuens.

A Justiça é a constante e perpétua vontade de dar a cada um o seu direito.

Iuris praecepta sunt haec: honeste vivere, alterum non laedere, suum cuique tribuere.

Os preceitos do direito são estes: viver honestamente, não lesar a outrem, dar a cada um o que é seu.

Ius naturale est quod natura omnia animalia docuit.

O Direito Natural é o que a natureza ensinou a todos os animais.

Hominum causa omne ius constitutum est.

Todo direito foi constituído por causa do homem

As Pandectas iriam influenciar todo o Direito ocidental, por meio dos juristas alemães do século XIX, que se propuseram ao estudo de um Direito Romano atual, adequado para o novo tempo, e tiveram seus nomes inscritos como astros de primeira grandeza no universo jurídico.

Ainda, no mesmo século VI, Justiniano mandou fechar as escolas de Atenas e criou a escola de Constantinopla. No entanto, esta ainda não tinha produção literária própria. E teve de se valer dos textos latinos e dos textos gregos, acessíveis pela tradução latina, que foram, assim, preservados.

9 JUSTINIANO. Instituições ou Institutas. Belo Horizonte: Champagnat, 1963. 
A redescoberta e a reintrodução do Direito Romano na Europa Ocidental, no século XII, com os Glosadores, seguidos dos Pós-Glosadores e dos Comentadores, antecipa, no Direito, a Renascença.

Os trabalhos das escolas medievais se agitam e se renovam, quando Aristóteles é reintroduzido na Europa, pela tradução dos árabes e por seus comentadores, Avicena e Averroés.

O século XIII é a idade de ouro da Escolástica e do desenvolvimento das Universidades. ${ }^{10}$

Até o século XV, quando, com o Renascimento, o mundo medieval se esgarçará, as Universidades, com suas controvérsias e sua autoridade, atraem a atenção do mundo culto.

Em Bolonha, o trabalho dos glosadores renova os estudos do Direito Romano.

Em Salamanca se discute se os índios da América poderiam ser considerados como titulares de direitos.

Entre a Universidade de Paris, conduzida pelos dominicanos, e a de Oxford, dos franciscanos, trava-se, entre realistas e nominalistas, a principal controvérsia medieval, a dos Universais.

Com a Renascença, a reintrodução de Platão na cultura ocidental pela cultura bizantina, o advento da nova ciência e a descoberta do Novo Mundo, nova idade de ouro se anuncia.

Os destinos do saber, nessa fase da história, nos induzem a lembrar de Castro Alves, quando, no belo poema, $O$ Livro e a América, diz:

10 Cf. REALE, Giovani; ANTISERI, Dario. História da filosofia: antiguidade e idade Média. Vol. I. São Paulo: Paulinas, 1990, p. 478 et seq., RUSSELL, Bertrand. História da filosofia ocidental. Vol. II. São Paulo: Companhia Editora Nacional, 1969, p. 156 et seq. e GIORDANI, Mário Curtis. História do império bizantino. Petrópolis: Vozes, 1977, p. 284 et seq. 
Por uma fatalidade

Dessas que descem do além,

O século que viu Colombo

Viu Gutenberg também. ${ }^{11}$

O alargamento das fronteiras do mundo coincide com o alargamento das fronteiras da cultura. Com a descoberta dos tipos móveis de impressão, e, sobretudo, com o aprimoramento da manufatura do papel, que o torna abundante e barato, o livro deixa de ser um artigo de luxo e se torna acessível ao povo. A leitura é facilitada, o ensino é popularizado e, apesar das caças às bruxas, dos anátemas das heresias pela intolerância religiosa, abrem-se novos horizontes de liberdade para o espírito humano.

\section{Entre o velho e o novo}

No Direito, o pensamento jurídico dos séculos XVII e XVIII é dominado pelo racionalismo jurídico.

Entre a preservação do saber antigo e medieval e o sopro de renovação do conhecimento, a nova era clama por inovação.

O jusnaturalismo culmina por advogar a elaboração dos Códigos, como um momento supremo da razão humana.

Entra em cena, então, de modo vigoroso e apaixonado, o confronto entre a tradição e a renovação, com consequências práticas surpreendentes, na polêmica entre o movimento da codificação e a resistência ao advento dos Códigos.

Ainda ressoa, nos recintos das faculdades, a controvérsia entre a Escola Histórica do Direito e o movimento em prol da codificação, que iria preparar o terreno para a expansão do movimento da Exegese, após a promulgação dos Códigos.

11 CASTRO ALVES. Obra completa. Rio de Janeiro: Aguilar, 1986, pp 76-78.

Revista Brasileira de Estudos Políticos | Belo Horizonte | n. 103 | pp. 307-326 | jul./dez. 2011 
Mas o sectarismo obscureceu os frutos da discussão.

A Exegese acabou por criar uma camisa de força para o Direito, aprisionando-o em fórmulas dogmáticas, e a Escola Histórica acabou por ser identificada com o culto do passado, reacionário e resistente às mudanças.

\section{Tradição e Inovação. O que mudar e o que preservar. Nosso compromisso}

É inevitável que nos deparemos com a interrogação: nas heranças que recebemos no campo da cultura, o que mudar e o que preservar?

Não temos de ter compromisso com o que é novo somente porque é novo.

Como não temos de ter compromisso com o que é velho e antigo, somente porque é velho e antigo.

Nem a antiguidade, nem a novidade constitui garantia de perfeição.

O nosso compromisso tem de estar em outro plano.

Se queremos soluções para a vida atual, não podemos consentir que as nossas heranças fiquem estagnadas, cristalizadas, engessadas no tempo.

A linguagem do passado serve para interpretar o passado, mas precisamos buscar a linguagem de nosso tempo para entender o nosso tempo.

Mário de Andrade diz, no "Prefácio Interessantíssimo" da Paulicéia Desvairada: "O passado é lição para se meditar, não para reproduzir". ${ }^{12}$

Não podemos pretender reproduzir, na vida, as soluções do passado, mesmo porque o passado não deu conta de resolver os seus conflitos, os seus problemas, muitos dos quais herdamos.

12 ANDRADE, Mário. Poesias completas. São Paulo: Martins, p. 29. 
O que deve ser preservado, em meio às mudanças, e deve ser renovado, sem se corromper com as inovações, é o que queremos proteger, é o que concebemos como um valor capaz de desafiar o tempo, é o que queremos universal.

\section{As promessas do século $X X$ na construção de um novo mundo. A Declaração Universal dos Direitos Humanos de 1948. A Declaração de Viena de 1993}

A história humana é cenário de incontáveis lutas pela liberdade, contra a tirania e a opressão, vindas de muitas instâncias.

O mundo conheceu várias Declarações de Direitos, que pretenderam ser uma garantia de proteção do indivíduo contra o absolutismo estatal e o abuso do poder.

As Declarações do século XVIII, que despontaram como uma garantia de direitos e liberdades, surgiram fortemente influenciadas pela ideia da existência de direitos inerentes à natureza humana, naturais e inalienáveis, eixo das doutrinas do Direito Natural.

No século XX, a Declaração Universal dos Direitos Humanos, de 1948, substitui o discurso do direito natural, como fundamento de direitos e liberdades, pelo da dignidade da pessoa humana, que há longo tempo vinha-se sedimentando na história. ${ }^{13}$

Precedendo aos trinta artigos, que seriam depois organizados nas cinco categorias de direitos - os direitos civis, os direitos políticos, os direitos sociais, os direitos econômicos

13 Aprovada em Paris, no Palácio de Chaillot, por meio da Resolução 217 A (III), em 10 de dezembro de 1948. Seus princípios básicos foram delineados na Carta das Nações Unidas, que instituiu a Organização das Nações Unidas, aprovada em San Francisco (EUA), em 26.06.1945. 
e os direitos culturais -, a Declaração compõe um preâmbulo cheio de promessas de construção de um novo mundo, fundado nos valores da Liberdade, da Justiça, da Paz e da Solidariedade.

Nesse Preâmbulo, ela faz o balanço do passado.Afirma que o desconhecimento e o desprezo dos direitos do homem conduziram aos atos de barbárie, causando indignação à consciência da Humanidade.Com os olhos no futuro, anuncia o advento de um novo mundo, em que os seres humanos, libertados do terror e da miséria, tenham a liberdade de falar e de crer. E proclama que o reconhecimento da dignidade inerente a todos os membros da família humana e de seus direitos iguais e inalienáveis constitui o fundamento da liberdade, da justiça e da paz do mundo. Os seus trinta artigos intentaram criar as condições para a concretização

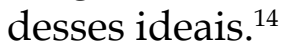

Em 1993, em um grande movimento que reuniu estudantes de todas as partes do mundo, profissionais liberais, religiosos, pessoas de todos os matizes políticos, de todos os credos e nacionalidades e delegações oficiais, foi proclamada a Declaração de Viena e Programa de Ação. ${ }^{15}$

14 À Declaração Universal de 1948 seguiram-se o Pacto Internacional sobre os Direitos Civis e Políticos, de 19.12.1966, e o Pacto Internacional sobre os Direitos Econômicos, Sociais e Culturais, de 16.12.1966, que entraram em vigor em 1976. Surgiram Convenções regionais como a Carta Africana de Direitos Humanos, a Convenção Americana de Direitos Humanos e a Convenção Europeia de Direitos Humanos. Sob a inspiração da Declaração Universal de 1948, foram promulgadas Declarações específicas como a Declaração Universal dos Direitos da Criança, de 1959, a Declaração Universal dos Direitos do Deficiente Mental, de 1971, a Declaração Universal dos Direitos das Pessoas Deficientes, de 1975 e a Declaração Universal dos Direitos dos Povos Indígenas, de 2007.

15 A Declaração de Viena, de 1993, foi adotada consensualmente pelas delegações oficiais de 171 Estados na II Conferência Mundial de Direitos Humanos, realizada em Viena de 14 a 25 de junho de 1993. 
Ela reafirma os compromissos e os direitos proclamados na Declaração de 1948 e ressalta a universalidade, a indivisibilidade, a interdependência e a interrelacionalidade das categorias dos direitos humanos.

Reafirma que todos os direitos do homem derivam da dignidade e do valor inerente à pessoa humana e que a pessoa humana é o tema central dos direitos do homem e das liberdades fundamentais.

Oferece um programa de ação para a implementação dos direitos, com propostas para assegurar os direitos de pessoas e grupos que se encontram em situações desprotegidas e de risco, e para o ensino e a educação sobre direitos humanos.

A Declaração de Viena foi adotada, consensualmente, pelas delegações oficiais de 171 Estados. O clima favorável à implementação dos direitos alcançou ações estatais e realizações e projetos sociais de diversas magnitudes e procedências.

Ninguém duvidava mais de que, para o gozo dos direitos civis e políticos, é imprescindível a implementação dos direitos econômicos, sociais e culturais, assim como a concretização destes depende da efetivação daqueles. Sem o efetivo gozo dos direitos econômicos, sociais e culturais, os direitos de liberdade, de igualdade e de participação se tornam uma mera figura de retórica.

A ineficácia derivada da fragmentação dos direitos já havia sido ressaltada e denunciada em muitas ocasiões e por muitos meios.

No Século XIX, o mundo se encantou com o Código de Napoleão. Na França, por todos os lugares, exaltava-se a conquista da igualdade perante a lei. Essa conquista foi magistralmente ironizada por Anatole France, que colocou na fala do poeta Choulette, uma das personagens de $O$ Lírio 
Vermelho (Le Lys Rouge) estas palavras: "majestueuse égalité des lois qui interdit, au riche comme ou pauvre, de coucher sous les ponts, de mendier dans les rues et de voler du pain" ("majestosa igualdade das leis que proíbe ao rico como ao pobre dormir sob as pontes, mendigar pelas ruas e roubar o pão" $) \cdot{ }^{16}$

Os direitos de igualdade que, no século $X X$, se quis implementar, foram os direitos cujo gozo somente poderia ser garantido pela efetivação dos direitos civis e políticos, sociais, econômicos e culturais, indissoluvelmente unidos por uma relação de complementaridade.

\section{A Declaração do Milênio: ano zero}

No Direito, foram muitas as promessas do século XX.

No entanto, quando o século terminou, a miséria, o abandono, a violência e as guerras localizadas não haviam sido extirpadas. A mortalidade infantil, a subcondição das mulheres, a negação do direito de acesso aos bens da cultura, à educação e à saúde constituíam causa de sofrimento, mas também de vergonha para a humanidade.

Em setembro do ano de 2000, foi aprovada a Declaração do Milênio das Nações Unidas, assinada por 189 Estados. ${ }^{17} \mathrm{Nela}$, foram reafirmados os valores fundamentais da liberdade, da igualdade, da solidariedade, da tolerância e do respeito à natureza. Foi reconhecida a responsabilidade comum pela sua efetivação e foi renovado o compromisso com a promoção dos direitos civis, políticos, econômicos, sociais e culturais de todas as pessoas, em todos os países.

16 Apud WIEACKER, Franz. Storia del diritto privato moderno. Vol. II. Milano: Giuffrè, 1980, pp. 159-161.

17 A Declaração do Milênio foi adotada na $65^{\mathrm{a}}$ Reunião da Assembleia Geral da ONU (Cúpula do Milênio), realizada em Nova York de 6 a 8 de setembro de 2000. 
Os signatários proclamaram o empenho em fazer do direito ao desenvolvimento uma realidade para todos e de construir um mundo novo e melhor.

A ONU decidiu que era hora de "libertar nossos semelhantes, homens, mulheres e crianças das condições abjetas e desumanas" e, com base em diagnósticos realizados sobre os mais graves problemas do mundo, estabeleceu os Objetivos de Desenvolvimento do Milênio, a serem alcançados até o ano de 2015.

Os Objetivos do Milênio, que ficaram mundialmente conhecidos como Oito Jeitos de Mudar o Mundo, foram amplamente divulgados em vários idiomas. Foram assim enunciados:

1. Erradicar a pobreza extrema e a fome.

2. Assegurar educação básica e de qualidade para todos.

3. Promover a igualdade entre os sexos e a autonomia da mulher.

4. Reduzir a mortalidade infantil.

5. Melhorar a saúde materna.

6. Combater as epidemias e doenças.

7. Garantir a sustentabilidade ambiental.

8. Estabelecer parcerias mundiais para o desenvolvimento.

Houve uma incrível adesão às campanhas. O sentimento geral era de que, com o esforço de todos, o mundo poderia ser salvo.

A juventude já havia cantado We Are The World na década de 80 para combater a fome na África. Agora, com os oito jeitos de mudar o mundo definidos, todos poderiam se unir nos mesmos laços de solidariedade.

No entanto, era o ano zero. Era o ano de 2000. 
Um ano depois, em setembro de 2001, nasceria o século XXI sob o signo do espanto e da violência.

A história recente nos mostra o que ocorreu. Novos atos de barbárie indignaram a consciência da humanidade.

Houve retrocessos nas conquistas de direitos e, por longo tempo, pareceu que a linguagem da força havia vencido a linguagem do Direito.

\section{9. $O$ que perdura}

Em meio a conquistas e derrotas, o mundo recomeçou a procurar outros caminhos para fazer com que a linguagem do Direito prevaleça sobre a da violência.

A convicção de que essa prevalência se dará pela efetivação dos direitos humanos se fortalece. Como assinala Mateus Afonso Medeiros: "não há como desconstruir a violência senão construindo os direitos humanos, senão [...] construindo a cidadania."18

No campo do Direito, muitas conquistas apontam para a ideia irrenunciável de se fazer um mundo melhor.

Outras parecem estar a caminho, surgindo lentamente, nas vias de acesso aos direitos e de proteção às pessoas.

Desde que os antigos conceberam a existência de direitos naturais e inalienáveis, desde que proclamaram, em Códigos, que todo direito foi constituído por causa do homem, o conceito de pessoa se prenunciou na história, foi ganhando seus contornos e a crença na dignidade da pessoa humana se consolidou e atravessou os tempos.

A pessoa humana se tornou o fundamento e o centro de todos os direitos.

18 AFONSO MEDEIROS, Mateus. Direitos humanos e violência. In: Direitos humanos: uma paixão refletida. Belo Horizonte: Rede de Cidadania Mateus Afonso Medeiros - RECIMAM, 2006, pp. 89-100. 
A dignidade de cada membro da família humana se converteu em valor universal, incondicional e inegociável.

A Pós-Graduação constitui um espaço privilegiado para que a Universidade continue a exercer o seu papel de preservar e construir o saber, de promover o debate e exercer a crítica e a reflexão que permitem as escolhas entre o que conservar e o que inovar.

Em 1948, Gustav Radbruch, Professor da Universidade de Heidelberg, escreveu um opúsculo, quase um panfleto, denominado Cinco Minutos de Filosofia do Direito. ${ }^{19}$

Nele, dizia como o povo e os juristas ficaram sem defesa contra as leis arbitrárias, cruéis e criminosas do nazismo. Sustentava que, quando as leis desmentem a vontade e o desejo de justiça, o caráter de jurídicas lhes deve ser negado. Afirmava que, embora os princípios do direito natural se achassem envoltos em graves dúvidas, o esforço de séculos conseguiu extrair deles as Declarações de Direitos, com sentido universal.

Radbruch era o que se chamava, na época, de um alemão puro.

Não sofreu perseguições em razão da raça.

Mas viu seus colegas e amigos perderem as cátedras e serem expulsos das Universidades porque eram judeus.

Viu os jovens de 18, 20 anos, matando e morrendo em nome de um desvario.

Viu que sua geração não deu conta de deter a perversidade e já não se podia contar com ela para mudar o mundo.

Ele não levou o seu Cinco Minutos de Filosofia do Direito aos editores.

Distribui-o na Universidade, como um panfleto, aos estudantes.

19 RADBRUCH, Gustav. Filosofia do direito. Vol. II. Trad. L. Cabral de Moncada. Coimbra: Arménio Amado, 1961, apêndice II, pp. 211-214. 
Acredito que, tal como Justiniano, que dedicou as Institutas à juventude do Império Romano, Radbruch sabia que, nos tempos em que o mundo parece enlouquecido, podemos ter esperanças na aurora de um novo dia, quando a juventude está a caminho.

Na década de 60 do século passado, os estudantes citavam, recorrentemente, a Décima Primeira Tese Contra Feuerbach (1845), de Karl Marx, que diz: "Os filósofos se limitaram a interpretar o mundo diferentemente, cabe transformá-lo" ${ }^{20}$

Sabemos que teorias e normas, qualquer que seja a sua natureza, de Códigos nacionais ou de Declarações Universais, não se aplicam sozinhas e, sozinhas, não mudam a realidade.

Mas mudam a realidade e se aplicam pela ação humana.

A esse propósito, queria lembrar um pequeno verso de Mário Quintana, de três linhas, que encontrei outro dia, ao visitar uma livraria:

Livros não mudam o mundo, quem muda o mundo são as pessoas.

Os livros só mudam as pessoas.

Muito obrigada.

Belo Horizonte, 22 de setembro de 2011

20 MARX, Karl. Teses contra Feuerbach. Trad. José Arthur Giannotti. In: MARX, Karl. Manuscritos econômicos-filosóficos e outros textos escolhidos. São Paulo: Abril Cultural, 1974, p. 59. 


\section{Referências}

AFONSO MEDEIROS, Mateus. Direitos humanos e violência. In: Direitos humanos: uma paixão refletida. Belo Horizonte: Rede de Cidadania Mateus Afonso Medeiros - RECIMAM, 2006.

ANDRADE, Mário. Poesias completas. São Paulo: Martins, s.d. ARISTÓTELES. Política. In: Obras. Madrid: Aguilar S.A, 1982.

BOBBIO, Norberto. O tempo da memória: de senectude e outros escritos autobiográficos. Rio de Janeiro: Campus, 1997.

CASTRO ALVES. Obra completa. Rio de Janeiro: Aguilar, 1986.

DONNE, John. Meditações. Trad. Fábio Cyrino. São Paulo: Landmark, 2007.

GIORDANI, Mário Curtis. História do império bizantino. Petrópolis: Vozes, 1977.

JUSTINIANO. Instituições ou Institutas. Belo Horizonte: Champagnat, 1963.

MARITAIN, Jacques. La personne et le bien commun. Paris: Desclée de Brouwer, 1947.

MARX, Karl. Teses contra Feuerbach. Trad. José Arthur Giannotti. In: MARX, Karl. Manuscritos econômicos-filosóficos e outros textos escolhidos. São Paulo: Abril Cultural, 1974.

MATA-MACHADO, Edgar de Godoi da. Contribuição ao personalismo jurídico. Belo Horizonte: Del Rey, 1999.

MEIRELES, Cecília. Obra poética. Rio de Janeiro: Nova Aguilar, 1987. 
RADBRUCH, Gustav. Filosofia do direito. Vol. II. Trad. L. Cabral de Moncada. Coimbra: Arménio Amado, 1961.

REALE, Giovani; ANTISERI, Dario. História da filosofia: antiguidade e idade Média. Vol. I. São Paulo: Paulinas, 1990. RECASÉNS SICHES, Luis. Tratado general de filosofía del derecho. México: Porrua, 1975.

RUSSELL, Bertrand. História da filosofia ocidental. Vol. II. São Paulo: Companhia Editora Nacional, 1969.

WELLS, H.G. História universal. Vol. III. Trad. Anísio Teixeira. São Paulo: Nacional, 1972.

WIEACKER, Franz. Storia del diritto privato moderno. Vol. II. Milano: Giuffrè, 1980. 